\title{
Extracurricular Activities Are A Key Element In The Organization Of The Educational Process
}

\author{
${ }^{1}$ G. Narkabilova, ${ }^{2}$ Sh.Khujamberdiyeva \\ ${ }^{1} \mathrm{PhD}$, lecturer at Fergana State University, Uzbekistan. \\ ${ }^{2} \mathrm{PhD}$, lecturer at Namangan State University, Uzbekistan.
}

\begin{abstract}
Article History:Received:11 January 2021; Accepted: 27 February 2021; Published online: 5 April 2021
Abstract: The article describes the factors, conditions, the principle of communicative activity (as a component of the principle of activity), signs, opportunities in creating conditions for the development of many areas of the student's personality, goals, objectives, content and forms of extracurricular activities. A systemically organized extracurricular lesson includes methods of teaching, upbringing and development that stimulate students to master knowledge and skills on their own, and also disposes to more informal interaction with teachers, which leads to the disappearance of the framework of the formal relationship and the disclosure of the internal potential of students.
\end{abstract}

Key words: goals, objectives, content and forms of extracurricular activities,

classroom and extracurricular activities, factors, conditions, the principle of communicative activity.

\section{Introduction}

Modern education is aimed at transmitting to future generations the experience, traditions and culture, practical and scientific knowledge accumulated by mankind in the process of historical formation and development. The content, system and forms of organization change in accordance with the development of science, the social, economic and cultural state of society, and taking into account the needs of young people and the prospects for the development of society. The process of improvement of the educational system, the inclusion of various technologies, forms and methods, requires taking into account the prospects of future professional activities of graduates.

More recently, the flow of information has doubled every five years, and the progressive development of science requires the involvement of both classroom and extra-curricular activities in the education system. Today, education standards require that the teacher teach students to acquire knowledge, continuously expand and enrich their horizons.

The successful establishment of a culture of communication among students at all levels of education is possible through systematic educational activities. Classrooms and extra-curricular activities can be part of the system. Classroom classes are the type of activity in which a set of goals, tasks within a limited time and a certain number of students are implemented. The classroom activities are determined by the curriculum, which takes the form of lectures, seminars, workshops and laboratories. The content of classroom activities is determined by the State educational standard, normative educational programmes and curricula. The effectiveness of a modern occupation depends on well-thought-out goals, content and the interests and needs of the students.[1] Instructor-led courses provide for the planning and systematic organization of educational activities, as well as constant monitoring of the results of the educational and cognitive process of students.

\section{Materials and methods}

However, this form of activity has its limitations in the creative organization of the educational process; Shaping and developing the qualities of the student, both personal and professional; Individualization and differentiation of the educational process; In the education and upbringing of pupils and their effective social adaptation. These conditions can be successfully implemented in the form of out-of-school classes, which can be held in and out of institutions of higher education.

The Uzbek scientist Nurmanov A.T. identified the axiological and akmeological possibilities of out-ofclass activities and defined such activities as the possibility of preparing students for technology and effective communication technology. Utanov U.S. considers the use of out-of-class activities as an opportunity to improve the students' spirituality. Instructional classes, according to the author, are not always able to satisfy the spiritual needs and needs of students, do not provide opportunities for free entry into live communication in spiritual, moral and educational fields. The results of the research show that: that the dynamic effectiveness of the spiritual development of students requires the separation and separate study of out-of-class classes as an independent form of upbringing and education from the complex and multifaceted development of the teaching and educational work of the university. In our turn, we have come to the conclusion that the process of developing the spirituality of students in out-of-class activities, while complex and multifaceted, can be 
effective only if the content, form and methods of out-of-class activities in the social humanitarian field are studied General professional and specialized subjects of the syllabuses. [2]

The scientist believes that extracurricular activities are a systematic educational process of students in their free time during the school year (semester), which takes into account mass, group, individual forms in socialhumanitarian, general and special subjects. [3; p.38]

In studies by E. V. Meshcheryakova, extra-curricular work implies a set of transformative actions carried out outside the educational process in direct connection with it. The research focuses on the principles of relevance, activism, and the principle of mass mixing; group and individual forms of work, highlights the principle of binarity, i.e. E. V. Meshcheryakova considers the principle of communicative activity (as a component of the principle of activity) to be an important principle in the organization of extra-audit work. [4]

E. P. Medynski also believes that the main focus of extra-curricular activities, above all, should be the overall cultural development of the human being. It highlights such features as:

- The individual character of human development and personal self-sufficiency;

- Meeting the individual needs of each through various forms - theatres, museums, clubs, etc. ;

- Not limited to a rigid programme;

- $\quad$ Full spiritual autonomy;

- The absence of coercion in recruitment;

- Each student is to some extent subject to his or her own forms of extra-curricular activity.

He also singled out such extra-curricular functions as:

- Acquisition and expansion of knowledge;

- Deepening the knowledge acquired;

- To improve the professional skills of specialists;

- The development of intelligence and personality at all ages;

- Introduction to cultural values;

- $\quad$ self-development and self-development. [5]

Extra-curricular activities have great potential in creating conditions for the development of many areas of the student's personality. The objectives, tasks, content and forms of extra-curricular activities include a wide range of independent work. Structured extra-curricular activities include teaching, education and development methods that encourage students to learn their knowledge and skills on their own, and to engage in more informal interaction with educators, which leads to the disappearance of formal attitudes and the development of students' internal capacities.

Outside the classroom, students are provided with unique opportunities to perform informal tasks and to expand the content of study assignments in extra-classroom work, which are transformed into the creative activity of the student and create the need to develop a deep layer of human knowledge and experience. Extracurricular work has considerable potential for realizing the cognitive activities of students, which began in their academic activities. Extra-curricular activities create the conditions for stimulating the development of the intellectual sphere of the individual and contribute to the development of his or her strong-willed qualities, which also make it possible to arouse interest in self-education and self-education. [6] Forms of extra-classroom work are not inserted into the frame and are unlimited in time. The various forms of extra-curricular activities make it possible to involve the student in various types of relationships accompanied by a favourable emotional mood and a positive psychological atmosphere.

U.S. Utanov identifies forms of extra-curricular activities such as research and teaching circles, theme evenings in disciplines, Olympics, clubs, excursions and expeditions, art weeks, pedagogical practice, Spiritual and educational events and popular events and national festivals forms of practical work, exhibitions, clubs. [3; p.38]

On the basis of literature analysis, extracurricular activities can be classified into traditional and nontraditional types. 


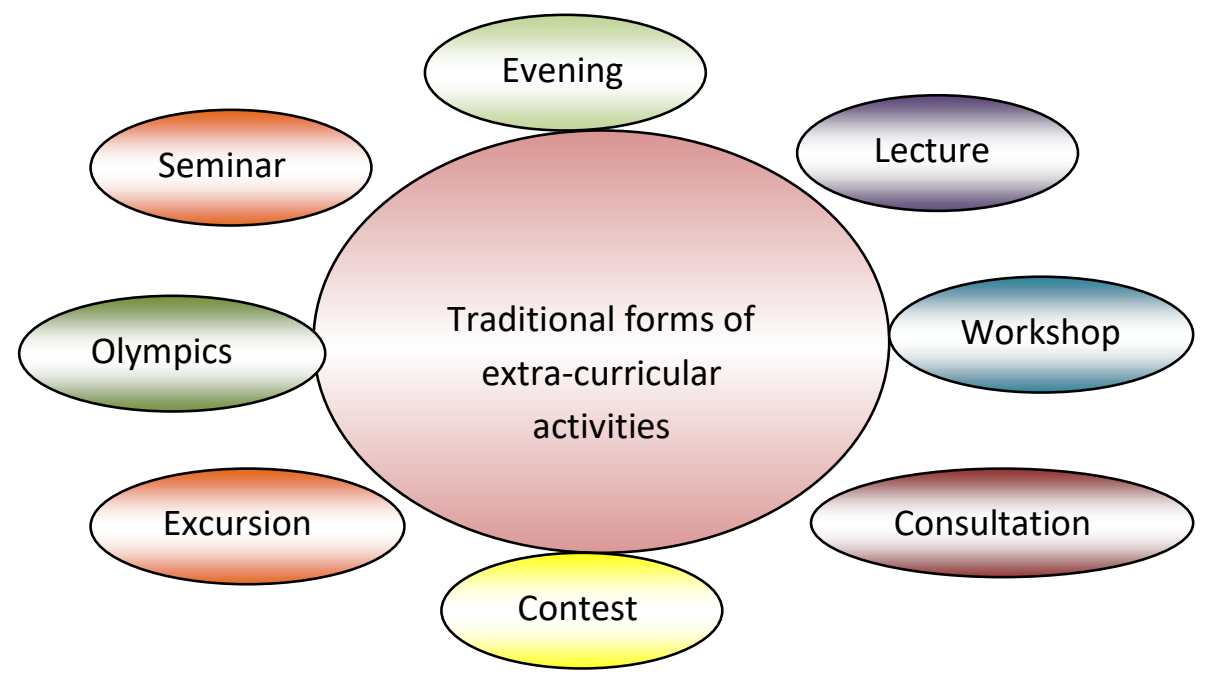

Figure 1. Traditional forms.

A large number of non-traditional occupations are based on the use of information technology.

Both traditional and non-traditional occupations are being used to improve and foster a culture of communication.

\section{Discussion}

The organization of extra-curricular work on the formation of a culture of communication among students includes the use of a large number of individual and collective tasks aimed at the development of creative potential. The performance of such activities in higher education and at home develops a positive emotional response to activities related to self-education, gives it joy and satisfaction. Research, applied, creative and cognitive tasks influence the emotional behavior of students and increase their positive attitude. Out-of-school classes, unlike those in the classroom, do not influence the rating of students, and stimulate them to form a positive reaction. Often, students also infect other students and motivate others to become interested in the process. One of the benefits of extra-curricular activities is that they are voluntary. The student participates in various events, competitions, webinars voluntarily. In contrast to the classroom classes, where the student controls attendance, which subsequently affects the whole result, the out-of-class classes satisfy the students' cognitive desires. Extra-curricular activities provide students with a range of activities and a wide range of interactions with teachers and students. In the out-of-class classes for the improvement of communication skills, intensive communication with the teacher is taking place, and student-to-student relations are being improved in the preparation of various forms of out-of-class activities. Formal and informal interaction between teachers and students is of great importance in improving the culture of communication among students. These relations foster creative cooperation between these actors, which stimulates interest in acquiring communication culture skills and imparts to them the knowledge needed in this activity. The gradual acquisition by students of the knowledge and skills required for effective communication (under the guidance of teachers and later independently) stimulates interest in the process. Evaluation and self-assessment of performance play a special role in demonstrating a positive emotional attitude towards improving communication culture skills.

Classroom work is based on formal work and extra-curricular work is based on informal interaction between the teacher and the student. In the process of extra-curricular activities, conditions are created in which informal relations between teachers and students are created, which helps in the preparation and conduct of mass or club activities, the development of friendly and partner relations in the evaluation of results. The development of such relations enables educators to show both demanding and respectful attitudes towards young people, while showing the positive and negative aspects of their extra-curricular activities, the causes of difficulties in the communication process, to reveal the ways and means of this process. Out-of-school classes cannot be conducted by authoritarian-minded students, which can block student activism and self-sufficiency, and make it impossible for students to develop an interest in further acquiring communicative skills and creativity. Students are not attracted to extra-curricular work, which is constantly oriented towards mastering students' already known knowledge in known ways. They seek to broaden and deepen their knowledge and skills and to establish friendly contacts with the teacher. A teacher needs to be able to feel the pedagogical situation, the specific team and the personality of each student. A pedagogically justified goal, a well-chosen material for the out-of-class work with students, precisely chosen methods and forms of working with students are possible if the pedagogue knows the method of optimal choice, Focuses on the best possible training options. The optimal choice of goals, content, methods, means and forms of extra-academic work ensures 
creative activity, autonomy and self-improvement of students, creates conditions for developing interest in communication among students. The conditions necessary for an effective establishment are also created through the successful implementation by the teacher of the principle of individualization and differentiation in the education, upbringing and development of students. Objective conditions for individualizing and differentiating work with students are created in out-of-class classes. Using a variety of individual and group forms of work, the teacher simulates a system of out-of-class activities, including context-specific forms of work, which allow the process of improving and forming students in communicative activities, Taking into account the tendencies and abilities of students, their needs and cognitive interests. Learning outside the classroom can potentially be an important means of developing the intellectual, voluntary and emotional sphere of a student's personality. Not all extra-curricular activities contribute to this.

Extra-curricular activities, just as every system, are made up of components such as objectives, content, methods, means and forms of teamwork, must be geared to the student's need for communication. The goals, objectives, content and forms of extra-curricular activities make it possible to make wide use of different types of tasks and works. Developing students' interest in improving their communication skills depends on how much students discover their need for life.

There are several factors that have a bearing on the success of extra-curricular activities: selected disciplines and environmental phenomena that are of interest and desire; techniques used by the teacher: home experiment, elements of developing and problem learning, approval, etc. ; Teacher incentives beyond the educational process: emphasizing the importance of a culture of communication; Incentives in the learning process itself: attracting the latest science and technology, reviewing the literature on the subject, showing the practical significance of the material, showing prospects for different professions, etc.; Methods and forms of organization of educational activities, solving problems requiring free orientation in the subject; Educational interest in a particular area of knowledge; Social motives (place in life, awareness of the importance of knowledge, self-improvement); Professional interest connection to life.

\section{Result}

As a result, students develop an interest in learning and learning in the course of pedagogically wellthought-out out classes. The readiness of students to engage in educational activities is also formed in connection with their mastery of historical and cultural heritage, which shows the role of self-education in achieving professional skills, social recognition, harmony and perfection. The various forms of organization of out-of-school activities and the teaching, upbringing and development methods used by the teacher encourage students to develop a focus on the acquisition of knowledge and skills on the culture of communication. Most forms of extra-curricular activity encourage students to be creative and to communicate more freely. The variety of extra-curricular activities allows them to test and introduce them into their own self-learning activities (especially successful in group cyclical work outside the classroom, where the educator can create the conditions for a systematic search for ways, means and means to improve the process of self-education, as well as to act as a consultant).

The correct selection of tasks in the extra-curricular activities (individual and joint) not only creates conditions for stimulating the development of the intellectual sphere of personality, but also promotes the development of the student's strong qualities, ensuring, them also awakening interest in communication. The head of extra-curricular activities can control the duration of the process by gradually improving the students' communication skills and stimulating their need for arbitrary activity and self-control. One important aspect is the systematic activity of students in the out-of-class work process. Students may be proactive, willing to participate in many activities, but their actions are usually spontaneous, depending on the mood. Only the organization of systematic activities of students in acquiring communication skills ensures that students develop an interest in this activity. In extra-curricular work, the teacher has the opportunity to create conditions for systematic self-education of students, especially in the work of creative association of students. The purposeful nature of the classes in developing the interest of students in self-education directs the teacher to teach the students to communicate and to commit themselves to fulfilling various tasks, including assignments. Extracurricular work creates unique opportunities for the development of students' emotional sphere. The material that every student learns outside the classroom ensures the development of his emotional sphere. Students under the guidance of a teacher and independently are encouraged to master material that reveals the harmony of peace, human relations. It is only the content of the out-of-class classes that allows to develop the emotional sphere of students.

\section{Conclusion}

We conducted an analysis of the possibilities of out-of-school work as a contributing factor to the improvement of students' communication skills, taking into account the data obtained from the analysis of scientific, Educational and methodological literature on the problem and status of the practice of organizing out- 
of-class work with students. The material of this paragraph leads to the conclusion that pedagogically wellorganized extra-curricular work stimulates students' readiness to acquire new knowledge, skills and abilities based on the development of intellectual, Voluntary and emotional spheres of the individual through the inclusion of students in active joint creative activities with teachers and fellow students, which contributes to the successful improvement of students' interest in self-education.

\section{References}

1. Atayeva N. Salayeva M.Khasanov S.Umumiy pedagogica (Ta'lim nazariyasi va amaliyot asoslari ). Darslik .2 kitob.-T:. 2013928317 bet

2. Nurmanov A.T. Preparing students for the technology and techniques of effective communication. - T.: Fan, 2010.- $110 \mathrm{p}$.

3. Utanov U.K. Auditoriyadan tashqari mashulotlar jarayonida bo'lajak o'qituvchi shahsi manaviyatini shakllantirish (Monograph). -T.: "Fan va texnologiya ", 2016, 144 Bet, p. 39

4. Meshcheryakova EV Out-of-class work in a pedagogical institution as a factor in preparing future teachers for out-of-class work with schoolchildren: Author's abstract . dis . Cand. ped . Sciences. / E.V. Meshcheryakova. - Volgograd, 1994 .-- 20 p .

5. Dudkina M.V., Kovalev V.P. Out-of-class activities as part of students' education and leisure // Bulletin of ChGPU im. I.Ya. Yakovleva. 2012. No. 1 (73). Part 1 p. 39

6. Kazarenkov V. I., Kazarenkova T. B., Litvinov A. V. "Extracurricular work as a factor in the formation of students' interest in self-education" Akmeologiya , \# 4 (60), 2016, pp . 225-231. 